\title{
Evaluation of the topical antiperspirant effects of a simple herbal formula
}

\author{
Ping-Chung LEUNG ${ }^{1,2 *}$, Patrick Chi-Leung HUI ${ }^{3}$, Frency Sau-Fun NG ${ }^{3}$, Clara Bik-San Lau ${ }^{1,2}$, King-Fai CHENG ${ }^{1,2}$, Winnie Wing-Man \\ LO $^{1,2}$, Ping CHOOK ${ }^{1,2}$ and Ellie Suet-Yee PANG ${ }^{1,2}$ \\ ${ }^{1}$ Institute of Chinese Medicine, The Chinese University of Hong Kong, Hong Kong, China \\ ${ }^{2}$ State Key Laboratory of Phytochemistry and Plant Resources in West China, Chinese University of Hong Kong, Hong Kong, China \\ ${ }^{3}$ Institute of Textiles and Clothing, The Hong Kong Polytechnic University, Hong Kong, China
}

\begin{abstract}
Background: Individuals with hyperhidrosis have much higher than average sweat rates. Topical application of herbal preparation may be effective in sweat control. Objective: The aim of this study was to evaluate the sweat control efficacy of an herbal preparation applied directly on the sole in healthy individuals using an electronic device SUDOSCAN.

Methods: Twenty healthy volunteers were screened and thirteen volunteers were eligible for the study.

Results: $84.6 \%$ of volunteers experienced a sweat reduction after 15 minutes of foot immersion in the herbal bath. The reduction reached an average of $15.3 \%$.

Conclusion: The herbal formula positively reduces sweating when applied topically.
\end{abstract}

\section{Introduction}

Although sweating is a normal physiological process, excessive sweating (hyperhidrosis) imposes a significant negative impact on the quality of life of individuals, through the embarrassing experience which also reduces self-confidence and social acceptance. This negative impact is further exacerbated by the production of unpleasant odour secondary to bacterial growth at the site. Many individuals use antiperspirant /deodorant products to control sweating and odour. Some chemical antiperspirants are effective, however, the side effects like allergy and irritations are also obvious [1]. The adverse effects caused by chemical antiperspirants could be avoided by using natural plant extracts. In ancient records the plants used for anti-perspiration by the Chinese people, include mulberry leaves (in "Danxi's Mastery of Medicine" and "Yi Shuo"), Huang Qi and Qin Pi [2]. These herbs are classified as having cool and cold property, thus manage to regulate sweating. Moreover, these herbs also possess strong antibacterial properties $[3,4]$, which could serve as deodorant.

In the present study, we chose mulberry leaves and Qinpi to form a simple combined formula, to be tested against sweating in the feet. Copious Sweating from the sole and digits of the feet would favour the foot to be chosen as the test site.

\section{The Testing Device - SUDOSCAN}

The SUDOSCAN is a device approved by the FDA of USA for the quick evaluation of sweat gland function through galvanic skin responses. SUDOSCAN measures the ability of the sweat glands to release chloride ions in response to an electrochemical activation on the palm of the hands and soles of the feet to be treated. Palms and soles are having the highest sweat gland density.

SODOSCAN provides quantitative measures of the sweat conductance on the hands and feet (in units of micro-Siemens). These measures can be conveniently used to compare the results before and after topical treatment against sweating [5]. Sweat glands are innervated by small unmyelinated sympathetic $\mathrm{C}$ nerve fibers.

The technology of SUDOSCAN uses low direct-current (DC) stimulation to extract chloride ions from sweat to create a current when these electrically charged ions encounter specific electrodes. SUDOSCAN can measure electrochemical skin conductance (ESC) of hands and feet through reverse iontophoresis.

ESC measures $<40 \mu \mathrm{S}$ indicate high sweat dysfunction; ESC measures between 40 and $60 \mu \mathrm{S}$ indicate moderate sweat dysfunction; ESC measures $>60 \mu \mathrm{S}$ indicate no sweat dysfunction (normal sweat function) [5].

\section{The pilot study}

In this study, we aimed to determine the efficacy of the antiperspirant herbal formula against sweating in the sole of feet by using SUDOSCAN to measure sudomotor functional changes in healthy volunteers before and after immersing the feet in standard herbal baths.

The pilot study was designed as a self-control prospective study,

Correspondence to: Ping-Chung Leung, Centre for Clinical Trials on Chinese Medicine, 5/F, The CUHK Hong Kong Jockey Club School of Public Health Building, Prince of Wales Hospital, Shatin, NT, Hong Kong SAR, Tel: (852) 2252 8868; Fax: (852) 2632 5441; E-mail: pingcleung@cuhk.edu.hk

Key words: herbal formula, antiperspirant, SUDOSCAN

Received: November 12, 2016; Accepted: December 09, 2016; Published: December 12, 2016 
SUDOSCAN device was used to measure the changes of the sweating function of the sole before and after soaking in a standard herbal formula bath.

As the study was a small sample size pilot study to assess the sweat control efficacy by using a noninvasive measurement, the administration route was topical and the study herbs are safe and commonly used, we did not ask participants provide written consent. However, we had verbal informed consent of all participants. We also have participants' identifying information such as subject number, name and contact number.

The volunteers were healthy males or females aged over 18 years without known sweat dysfunction.

SUDOSCAN consists of two sets of stainless-steel electrodes in contact with the palms of the hands and soles of the feet. A special computer was responsible for recording and data management (Figure 1).

After resting in the study room for 15 minutes, the volunteers were required to immerse their feet in body temperature water, then the standard herbal bath, as tabulated:

\begin{tabular}{|l|c|}
\hline Testing Time point & SUDOSCAN Testing \\
\hline Baseline & $1^{\text {st }} \mathrm{Scan}$ \\
\hline $36-37^{\circ} \mathrm{C}$ Water, $15 \mathrm{mins}$ & $2^{\text {nd }} \mathrm{Scan}$ \\
\hline $36-37^{\circ} \mathrm{C}$ Herbal Bath, $15 \mathrm{mins}$ & $3^{\text {rd }} \mathrm{Scan}$ \\
\hline 15 mins Resting (Residue effect) & $4^{\text {th }} \mathrm{Scan}$ \\
\hline
\end{tabular}

During the test, the subject placed his or her hands and feet on the electrodes (Figure 1). Data appeared automatically in the computer screen.

\section{Statistical methods}

The changes in SUDOSCAN measures at each time point were assessed by the General Linear Model, Chi square test, repeated measures analysis of covariance (ANCOVA) using baseline parameters as the covariate. The sweat reduction before and after herbal immerse was calculated as the mean of the sweat reduction values. Differences among time points were tested by one-way ANOVA for continuous variables and by $\chi^{2}$-test for categorical variables. All data analysis was performed using the Statistical Package for the Social Sciences (SPSS), version 22.0. Statistical significance was two-sided. Any difference with $p$ value less than 0.05 were considered significant.

\section{Results}

The testing environment $\left(22^{\circ} \mathrm{C}\right)$ apparently had limited effects on sweating. The temperature of water $\left(37^{\circ} \mathrm{C}\right)$ and herbal solution $\left(37^{\circ} \mathrm{C}\right)$ immersions was identical.

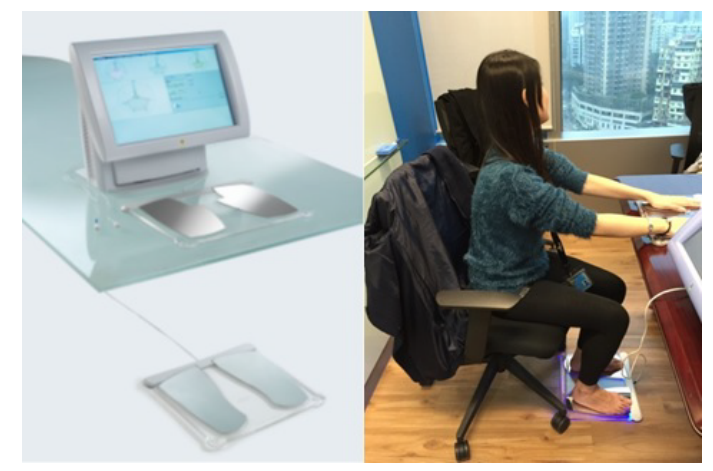

Figure 1. SUDOSCAN device and Sweat glands Testing with SUDOSCAN.

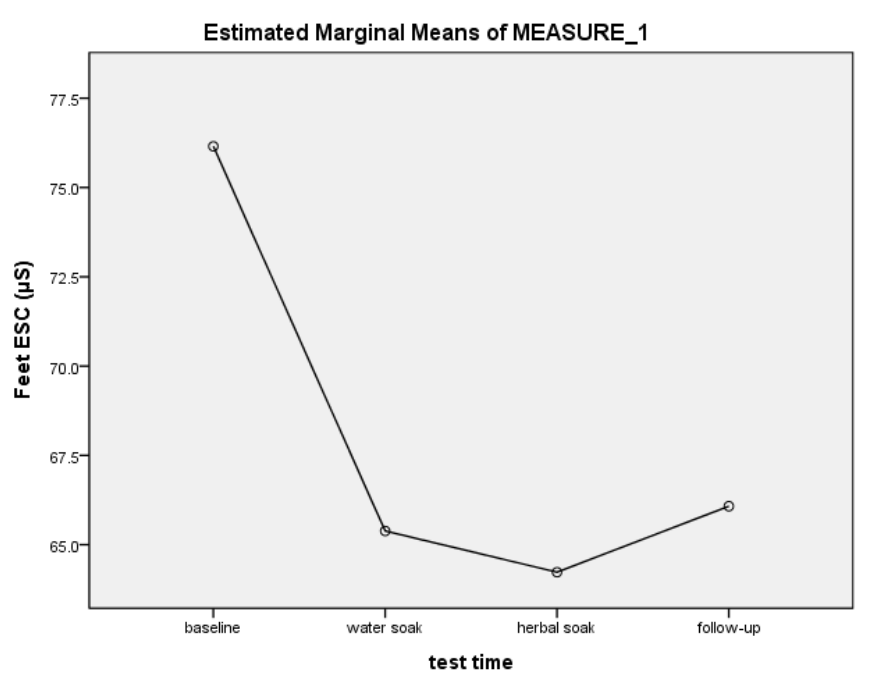

Figure 2. Changes of ESC measures at each time point.

Table 1. Demographics characteristics and SUDOSCAN outcomes of study subjects.

\begin{tabular}{|l|c|c|c|c|}
\hline & Baseline & Water soak & Herbal soak & Follow-up \\
\hline Feet ESC $(\mu \mathrm{S})$ & $76.2 \pm 7.1$ & $65.4 \pm 8.3$ & $64.2 \pm 11.3$ & $66.1 \pm 13.2$ \\
\hline Change in foot ESC $(\mu \mathrm{S})$ & -- & $-13.5 \%$ & $-15.3 \%$ & $-13.6 \%$ \\
\hline P value (vs. baseline) & & 0.001 & 0.003 & 0.000 \\
\hline
\end{tabular}

\begin{tabular}{llll} 
Baseline & $\stackrel{\mathrm{H}_{2} \mathrm{O} \text { immerse }}{\longrightarrow}$ Herbal Immers $\longrightarrow$ & Post Test \\
\cline { 2 - 2 } & $15 \mathrm{~min}$ & $15 \mathrm{~min}$ & $15 \mathrm{~min}$ \\
Test 1 & Test 2 & Test 3 & Test 4
\end{tabular}

\section{Recruitment}

Seven healthy males and 13 healthy females with a mean age of 32.6 years were screened. The volunteers fulfilling the following inclusion criteria were enrolled in the imprint casting studies: women and men at an age of 18 to 65 years. Thirteen subjects who met the study criteria were enrolled. Seven volunteers, whose ESC measures were less than 60 $\mu \mathrm{S}$ or showed abnormal sweating response, were excluded. Eventually altogether thirteen healthy volunteers entered the analysis (Table 2).

\section{Outcomes and estimation}

Results for quantitative variables are shown as means standard deviation. Repeated measurement analysis, adjusted with hand data as covariate, was used for the comparisons. A p value $<0.05$ was regarded as statistically significant.

ESCs of the feet were significantly decreased at various time points compared to their baselines in the treated group $(\mathrm{P}=0.001, \mathrm{p}=0.003$ and $\mathrm{P}=0.000$, respectively) (Table 1 ).

We randomly selected 8 subjects as controls to the 13 subjects. The control subjects were not given water or herbal bathing. They served to rule out the environment effects during testing. The results showed that the controls did not show decline in ESC. Effects of the herbal bath were thus reinforced (Table 3). Subjects soaked with herbal bath showed greater drop in ESC which was prolonged (Figure 2).

In treated group $(n=13)$, changes in response to $A$ (water immersing at $37^{\circ} \mathrm{C}$ ), B (herbal immersing at $37^{\circ} \mathrm{C}$ ) and $\mathrm{C}$ (aftermath of $\mathrm{A} \& \mathrm{~B}$ ) were shown Figure 3 In control group $(n=8)$, changes at various time points 
Table 2. Individual values of Demographics characteristics and ESC of hands and feet.

\begin{tabular}{|c|c|c|c|c|c|c|c|c|}
\hline Subj_No & \multicolumn{9}{|c|}{ Feet } & \multicolumn{4}{|c|}{ Hand } \\
\cline { 2 - 10 } & Baseline & $\begin{array}{c}\text { Water } \\
\text { soak }\end{array}$ & $\begin{array}{c}\text { Herbal } \\
\text { soak }\end{array}$ & $\begin{array}{c}\text { Follow- } \\
\text { up }\end{array}$ & Baseline & $\begin{array}{c}\text { Water } \\
\text { soak }\end{array}$ & $\begin{array}{c}\text { Herbal } \\
\text { soak }\end{array}$ & $\begin{array}{c}\text { Follow- } \\
\text { up }\end{array}$ \\
\hline DSS01 & 80.0 & 75 & 76.0 & 65 & 62.0 & 59 & 50.0 & 60 \\
\hline DSS02 & 81.0 & 65 & 58.0 & 55 & 70.0 & 57 & 50.0 & 42 \\
\hline DSS03 & 65.0 & 62 & 54.0 & 62 & 50.0 & 34 & 53.0 & 73 \\
\hline DSS04 & 78.0 & 70 & 70.0 & 71 & 59.0 & 47 & 37.0 & 57 \\
\hline DSS07 & 83.0 & 58 & 58.0 & 79 & 82.0 & 49 & 61.0 & 67 \\
\hline DSS09 & 81.0 & 52 & 50.0 & 65 & 54.0 & 27 & 34.0 & 59 \\
\hline DSS10 & 77.0 & 62 & 75.0 & 73 & 73.0 & 46 & 35.0 & 59 \\
\hline DSS11 & 80.0 & 83 & 80.0 & 79 & 87.0 & 88 & 89.0 & 80 \\
\hline DSS14 & 64.0 & 61 & 53.0 & 35 & 48.0 & 25 & 20.0 & 24 \\
\hline DSS15 & 78.0 & 73 & 78.0 & 80 & 70.0 & 62 & 63.0 & 72 \\
\hline DSS18 & 79.0 & 67 & 73.0 & 77 & 75.0 & 65 & 65.0 & 73 \\
\hline DSS19 & 81.0 & 57 & 50.0 & 68 & 75.0 & 50 & 43.0 & 60 \\
\hline DSS20 & 63.0 & 65 & 60.0 & 50 & 56.0 & 53 & 45.0 & 53 \\
\hline N & 13 & 13 & 13 & 13 & 13 & 13 & 13 & 13 \\
\hline Mean & 76.154 & 65.38 & 64.23 & 66.08 & 66.23 & 50.92 & 49.62 & 59.92 \\
\hline SD & 7.116 & 8.32 & 11.31 & 13.19 & 12.34 & 16.78 & 17.48 & 14.75 \\
\hline
\end{tabular}

Table 3. ESC measures of the two groups at each time point.

\begin{tabular}{|l|c|c|c|c|}
\hline Time point & $\mathbf{1}$ & $\mathbf{2}$ & $\mathbf{3}$ & $\mathbf{4}$ \\
\hline Treated $(\mathrm{ESC} \mu \mathrm{S})$ & $76.15 \pm 7.12$ & $65.38 \pm 8.32$ & $64.23 \pm 11.31$ & $66.08 \pm 13.19$ \\
\hline Controlled $(\mathrm{ESC} \mu \mathrm{S})$ & $75.13 \pm 6.01$ & $77.38 \pm 4.34$ & $78.63 \pm 3.93$ & $78.25 \pm 6.18$ \\
\hline P value & 0.737 & 0.001 & 0.001 & 0.025 \\
\hline
\end{tabular}

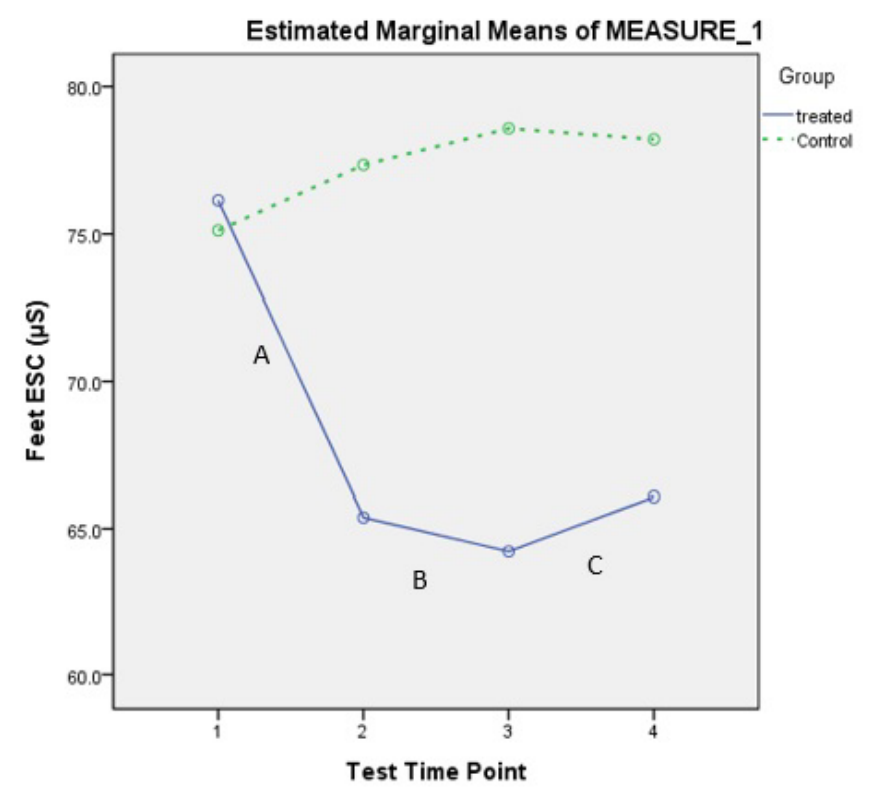

Figure 3. Changes of ESC measures between the two groups at each time point.

under office environment $\left(22^{\circ} \mathrm{C}\right)$ were also shown Figure 3. No subject reported allergic reaction during the course of the study.

\section{Discussion}

Aluminum chloride hexahydrate $(\mathrm{ACH})$ is commonly used in cosmetic preparations as antiperspirant. Many still consider it to be the most effective agent. However, irritations of the skin and damage to clothing remain its major disadvantages [1]. The extracts from Chinese herbs used as a topical antiperspirant would not only avoid the sideeffects caused by the inorganic antiperspirants but also follow the current trend of using natural material in the cosmetics industry.

The antiperspirant effects of Mulberry has been clearly recorded in the "Shennong's Classic of Materia Medica". Esculin hydrate, an active antiperspirant recorded in traditional Chinese herbal medicine, could be as effective [6,7].

Fraxinus rhychophylla, another Chinese traditional herbal medicine, has been studied in the laboratory in an artificial skin model using fluorescence analysis technique for comparison with aluminum polychloride with regard to antiperspirant effects. The results showed that the extracts from fraxinus rhychophylla had the similar effects as the aluminum polychloride [2].

Industries require that antiperspirants should have more than $20 \%$ sweat reduction in $50 \%$ of panelists before being accepted as reliable $[8,9]$. In this pilot study, we found that the average sweat reductions were $15.3 \%$ but the contact duration was only 15 minutes. The pilot study did demonstrate a trend of sweat reduction.

In conclusion, the pilot study on sweating control using SUDOSCAN evaluation demonstrated that soaking the feet with herbal bath containing Mulberry leave and Fraxinus rhychophylla extracts effectively reduced sweating.

\section{Acknowledgments}

This study is part and partial of a Grant Proposal under the Innovation and Technology Fund of the Hong Kong Government.

Special gratitude is given to the "8765 Diabetes" Clinical Services which kindly arranged the application of the SODOSCAN.

We gratefully acknowledge financial support from Innovation and Technology Fund of the Government of Hong Kong Special Administrative Region (Project Code: ITS/370/14).

\section{References}

1. Benohanian A (2001) Antiperspirants and deodorants. Clin Dermatol 19: 398-405. [Crossref]

2. XUE Yi-fen, ZHAI Shu-xian, WANG Jian-xin (2005) Screening of antiperspiratory ingredient in fraxinus rhychophylla. China Surfactant Detergent \& Cosmetics 35: 133136

3. Sun Li-jun, Chen Ling-ling (2004) Effects of sixChinese herbal medicines on Bifidobacteria and E. Coli in vitro JTCVM 1: 7-8.

4. Duncan SH, F1int H J, Stewart CS (1998) Inhibitory activity of gut bacteria against Escherichia coli $\mathrm{O} 157$ mediated by dietary plant metabolites. FEMS Microbiol Lett 164: 283-288.

5. Gin H, Baudoin R, Raffaitin C, Rigalleau V, Gonzalez C (2011) Non-invasive and quantitative assessment of sudomotor function for peripheral diabetic neuropathy evaluation. Diabetes \& Metabolism 37: 527-532.

6. XUE Yi-fen, WANG Jian-xin (2006) Synthesis of Qinpi active ingredients and its Application in cosmetics Jiangnan University Master Thesis.

7. Du Wu-xun, Tian Feng-ying (1997) Mulberry antiperspirant research) Journal of Tianjin College of Traditional Chinese Medicine 1: 8.

8. Cheng Yan, Qi Yan (2006) Efficacy evaluation for antiperspirants and deodorants. Chinese Journal Aesthetic Medicine 15: 743-744.

9. Philip Klepak and Jack Walkey (2016) Antiperspirants and deodorants (Eds,.) Butler H., Poucher's Perfumes, Cosmetics and Soaps 10: 69-100.

Copyright: (C2016 Ping-Chung LEUNG. This is an open-access article distributed under the terms of the Creative Commons Attribution License, which permits unrestricted use, distribution, and reproduction in any medium, provided the original author and source are credited. 